\title{
Las delicias del tiempo perdido (Notas indolentes sobre literatura americana y europea vistas con óptica colombiana) ${ }^{1}$
}

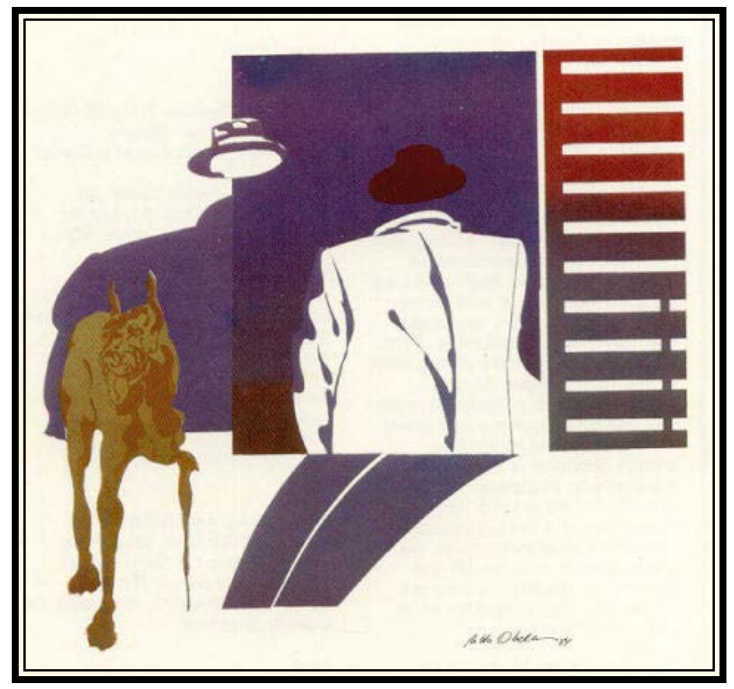

"Los españoles, también, van conociendo cosas. El pan cazabe, maíz, chicha, tabaco, la enfermedad de las bubas, hamacas, yuca, canoas, flechas, bancos de perlas, guerras, cocodrilos, mares, bosques en donde cada árbol es distinto de los árboles de España, cada pájaro canta una nueva canción, cada alborada muestra una montaña desconocida, cada lucha una experiencia deslumbrante, más deslumbrante que el oro que antes nunca vieron y que ahora pesa en el cuenco de sus manos temblorosas".

Germán Arciniegas. Biografía del Caribe.

En los viejos cafés bogotanos - luces biliosas, humo de cigarrillos, meseras que distribuyen, en admirable equilibrio, las numerosas tazas de tinto (café negro y no vino rojo, como podrían creer españoles y argentinos) - los hombres encontraban la posibilidad de acceder al único tiempo que parecía válido: el tiempo perdido.

Sabemos lo que es la acción, y los desdichados frutosqueentantas ocasiones produce.Loqueaún no hemos aprendido a valorar son las fecundas dimensiones del ocio. Con razón Lezama Lima afirma: "En el Trópico todo depende del estilo de la siesta". En la siesta, como en el café, fructifica la reflexión y se dilapidan, generosas, las ideas efímeras y geniales. Allí, en el café, tienen también cabida el diálogo salpicado de chismes, el ingenio verbal, la réplica instantánea o, más sencillamente, el letargo y la pereza asumidos, a fondo. No hacer nada: ¡qué proyecto tan arduo! ¡Qué empresa tan esforzada!

1 Este ensayo fue publicado en el libro El mausoleo iluminado. Antología del ensayo en Colombia, edición a cargo de Oscar Torres Duque, Bogotá: Presidencia de la República, colección Biblioteca familiar (1997). La ilustración es de la autoría de Pablo Obelar y Juan Gustavo Cobo Borda con una técnica de Serigrafia. Sus dimensiones son de $40 \times 58 \mathrm{cms}$ y corresponde al año de 1984. 
La fatalidad de la historia latinoamericana consiste, ante todo, en que se le obligó a tomar un sentido que no era el suyo. Se le impuso, encajonándola dentro de una utopía perversa: la del progreso. ¿Cómo salir de ese callejón sin salida? Mintiendo, tergiversando los hechos, trastocando los datos. Ficcionalizando, en definitiva, toda la banalidad de un existir absurdo. ¿Qué son El Aleph, La vida breve, Pedro Páramo, Rayuela, Gran Sertón: Veredas, Paradiso, Cien años de soledad, Conversación en la Catedral o Los ríos profundos sino el intento a la vez urgido y caviloso de retrasar el desmoronamiento de un tiempo que se anula a sí mismo y se devora en su inutilidad repetida, concretándolo en el flujo de una lengua, también ajena, y gracias a ellos por fin nuestra?

En una de las aproximaciones más agudas para comprender un país sui generis de América Latina, como es el caso de Argentina, el novelista triniteño V. S. Naipaul escribía, en 1972, en su crónica "El regreso de Eva Perón":

Quizás muy poco de lo que ocurre en Argentina es verdaderamente noticia, porque no hay ningún movimiento de avance, no se está resolviendo nada, la nación parece jugar consigo misma; y la vida política argentina es igual que la vida de una comunidad de hormigas o de una tribu de la selva africana: llena de acontecimientos, llena de crisis y de muertes, pero la vida no es más que un ciclo y el año siempre termina como empieza.

¿Alguna explicación? Naipaul insinúa lo siguiente: "No hay historia en la Argentina. No hay archivos; sólo hay graffitis en las paredes y polémicas y lecciones en la escuela. En la Argentina la historia es menos un intento de dejar constancia y entender, que un hábito de reordenar hechos inconvenientes; es un proceso deolvido". Cuando llegué a la Argentina, en 1983, y pregunté: ¿qué buena novela ha salido en estos años?, me respondieron: Ninguna. La realidad ha sido tan brutal que anuló toda ficción. Sí, por cierto, pero esa realidad, discutida, conversada y padecida, es ya irrecuperable. Se borró. Se hizo humo. Hace falta el novelista que la vuelva tangible. La verdadera historia latinoamericana, es bien sabido, está en nuestras obras de ficción.
De ahí - retorno al tema- la función casi sacramental que podía tener en Colombia, hasta los años 60, la hora del tinto. Era el recuento minucioso, y puesto en orden, de esas pequeñas intrascendencias que enriquecen, con lo sápido de su gusto, la gris molicie de todos los días. Al charlar, cotejar opiniones, intercambiar puntos de vista, estos historiadores amateurs estaban redactando su versión de la historia. Costumbre, rito, continuidad vacía sin la cual no podríamos definirlos. Era la pausa necesaria para saber qué había sucedido, e interpretarlo a su gusto. De ahí que la deformación sea el signo de nuestra historia. De nuestra historia oficial, bien entendido. La otra, poblada de anécdotas e insidias, es la verdadera. Allí se disuelve la rigidez formal gracias al aleteo de la risa; y el humor, malévolo, corroe toda verdad única, impidiéndole concretarse en una sola imagen fija. ¿Cuántos fueron los muertos de la matanza bananera, cuántos los de Canudos? Los que Gabriel García Márquez y Mario Vargas Llosa nos dicen.

La historia de América Latina no es sólo épica como quieren hacernos creer, a toda costa, en este año del bicentenario del nacimiento de Bolívar (1783-1830). Ni su secuencia es la abrumadora de fechas heroicas y efemérides perfunctorias. Ella es, ante todo, llanamente cotidiana. Y su música no es tampoco la de las dianas de Junín y Ayacucho, en la cual, como diría Borges, ella se encuentra con su destino sudamericano; ese destino que es siempre la muerte. Su ritmo es, en realidad, el del café, donde cualquier crescendo queda amortiguado por ese murmullo constante; esa conversación global que lo trasciende y anula, y del cual sólo con mucha atención podemos distinguir los matices. No se entiende nada pero allí está reunida gente que habla. Oigámosla, comencemos a percibirla.

Los españoles gritan, los italianos vociferan, los argentinos - a pesar de que la historia insiste en demostrarles lo contrario - todavía creen en sí mismos: hablan duro. En los momentos de sincera autocrítica no dejan de hacernos saber que ellos, jasombro!, han alcanzado el mayor índice de inflación del mundo. Pero quizás la dicotomía ya no sea posible establecerla entre el 
énfasis y la sordina. Rubén Darío hablaba, en el siglo pasado, del abate mexicano y el vizconde porteño, es decir, enfrentaba, en el casi imposible equilibrio latinoamericano, al indio ambiguo $\mathrm{y}$ fino $\mathrm{y}$ al inmigrante fuerte $\mathrm{y}$ prepotente, mejorado quizás ahora, en este invierno de su descontento. Sólo que hoy en día todos somos indios, colonizados por Europa, y que buscan en aquellas raíces - en su razón, en su técnica, en su religión y su política- los motivos no de su actual sino de su sempiterna indigencia. Pero al llegar a ella, a esa Alemania, por ejemplo, donde los hijos de los obreros son fascistas y los hijos de los ricos terroristas, todos sus profetas pregonan una cantinela semejante: soledad y desempleo, emigrantes y ecología. No diferimos del Tercer Mundo. Todos somos periferia y el centro no existe. ¡Que viva el irracionalismo!

No quedó entonces más remedio que volvernos a mirar a nosotros mismos; a este continente rico en expectativas no cumplidas y pobre en sus afligentes realidades inconmovibles, en el cual la vida política anda a tumbos; la autocensura, no sólo mental, resulta un recurso perfectamente válido para conservar la vida y su única institución sólida, el ejército, sigue siendo fiel a quienes lo moldearon en sus comienzos: instructores prusianos.

Idioma, religión, códigos, formas de pensamiento: todo nos vino de Europa y todo, afortunadamente, fue adulterado en el Nuevo Mundo. De un Trópico idílico pasamos a ser una pesadilla exuberante. De la distancia mágica con que se nos contemplaba nos convertimos en la voracidad feroz con que devorábamos todo cuanto estaba a nuestro alcance. Con razón en Brasil se creó el movimiento "antropofágico". Teníamos derecho a consumirnos a nosotros mismos, luego de haber asimilado todo cuanto Occidente ponía a nuestra disposición. Pero éstos eran puntos límites. ¿Alcanzaríamos algún día una comprensión real, a la vez sobria y desencantada? Quizás sí. Bastaba hablar de lo que fuimos, asumiendo una memoria perdida. En primer lugar, la del genocidio indígena.

Entre 1492 y 1550 la población indígena de México y el Caribe descendió de 25 millones a un millón, y en las regiones andinas, entre 1530 y 1750 , de seis millones a medio millón. Un pillaje, luego, enmarcado en el letargo de una burocracia lerda, la burocracia de los Austria que convirtió el Nuevo Mundo en una polvorienta notaría; $\mathrm{y}$, finalmente, una Utopía que al asentarse en tierra firme, saltó hecha pedazos. Oscila, ahora, entre la irrisión y la desesperanza. Las teorías eran de esta índole: el Trópico, tierra incógnita e incognoscible que, como la Madre Naturaleza, ofrece dos rostros: uno virginal, otro funesto. Pureza radiante o avidez succionadora. Paraíso anterior al pecado original; o "verde infierno" no sólo previo sino posterior a toda civilización, por más endeble que ésta haya sido. La selva invadirá, cómo no, estas ciudades corroídas por la mugre, deficientes en sus servicios públicos y circundadas por rostros oscuros que echarán por tierra, es inevitable, el aburrido mito de una blancura distinguida. Las ciudades son la nueva selva sucia. ¿En ella qué éxtasis, qué revelaciones son posibles?

Bolívar, en 1819 en su Discurso de Angostura, decía: "Es imposible asignar con propiedad a qué familia humana pertenecemos. La mayor parte del Indígena se ha aniquilado, el Europeo se ha mezclado con el Americano y el Africano, y éste se ha mezclado con el Indio y el Europeo. Nacidos todos del seno de una misma Madre, nuestros padres difieren en origen y en sangre, son extranjeros, y todos difieren, visiblemente en la epidermis". Esta desemejanza trae consigo un reto de la mayor trascendencia: fundir el caos en una unidad: la del mestizaje. La misma que hoy es perceptible en los habituales contertulios de cualquier café: el tono uniformemente oscuro de los trajes, la voz apagada del sigilo; la pobreza, en una sola palabra.

Nosotros, los indígenas del altiplano colombiano, parecemos desconfiar, a través de la cortés elusividad y de la amable hipocresía, de cualquier verdad que se pretenda exclusiva. Esto contribuye a volvernos aún más irreales pero nos permite también deslizarnos entre los intersticios de las afirmaciones rotundas. Pugnas de familia, discrepancias entre clanes y tribus; hordas de parientes detrás de los cuales la vacancia de los escudriñadores (no 
historiadores) descubre siempre los mismos apellidos: la historia como forma exaltada de la chismografía. Historia de pequeños pueblos, fundados hace dos, tres o cuatro siglos. Gente de paso, que todavía encuentra terrenos baldíos. De ahí que entre nosotros no fructifique la tragedia, ni que el ciclo habitual - mito, épica, tragedia - se cumpla, hegelianamente. Tanto la crónica como la lírica lo vulneran, elevando la tragedia a la categoría de melodrama. Espejo cóncavo, como decía Valle-Inclán, en el cual se reflejan nuestras muecas, a la vez irrisorias y agónicas, y en ocasiones tristemente límpidas: pienso en El coronel no tiene quien le escriba, y en la soledad como clave, ya no de los espacios desiertos sino de las almas enfrentadas a ellas mismas. Nuestra tensa y soterrada pugna para apaciguar el caudal de sangres enfrentadas que esterilizan a esos cuerpos desnutridos, y presos de sueños febriles. La literatura, como forma de entendernos a nosotros mismos. Terapia que nos revela nuestro destino.

Es común afirmar de nuestro país que es un país muy nuevo, en el sentido ufano de la palabra. Pero no es menos en otro; en el de desusado, torpe e inmaduro. Después de cuatro siglos de "conquista" el hombre es todavía un intruso en estos confines de América. Yo afirmo - sin remilgado temor ni novelero amor de la paradoja- que solamente los países nuevos tienen pasado; es decir, recuerdo autobiográfico de él; es decir, tienen historia viva. Si el tiempo es sucesión, debemos reconocer que donde densidad mayor hay de hechos, más tiempo corre, y que el más caudaloso es el de este inconsecuente lado del mundo. Yo no he sentido el liviano tiempo en Granada, a la sombra de torres cientos de veces más antiguas que las higueras, y sí en Pampa y Triunvirato, insípido lugar de tejas anglizantes ahora, de hornos humosos de ladrillo hace tres años, de potreros caóticos hace cinco. El Tiempo-emoción europea de hombres numerosos de días, y como su vindicación y corona - es de más imprudente circulación en esta república.*

El tiempo, en Alemania, se halla programado. Cada porción del mismo cumple un objetivo. Está destinado a algo. El placer, incluso, se obtiene no dejándolo al azar sino sometiéndolo a la planificación racional. No es un excedente que se dilapida sino una misión que se cumple. Quizás el proceso no resultase tan espontáneo, pero, en todo caso, su apropiación era mucho más segura. ¿Llegaremos a eso? ¿La felicidad por decreto? ¿El orgasmo por computadora? Los latinoamericanos, más volcados hacia lo inmediato (no lo concreto), más capaces de disfrutar el riesgo de lo imprevisto, y, en últimas, dependientes de la providencia divina, no han podido poner orden en sus vidas. Convirtiéndolas, al igual que los europeos, en algo pautado: impuestos, planes de vacaciones, previsión, seguros de vida, sitios donde se debe y no se debe parquear. Gracias a ello la vida en comunidad se hace posible y a la vez se convierte en algo muy insípido. (La superpoblación, es obvio, nos obligará a tomar medidas). Respeto sí, cómo no, pero también frialdad. Vecinos de los cuales, en veinte años, no llegamos a saber nada, y a los cuales todas las mañanas saludamos, con cortesía inalterable. ¿Y para qué saber algo, si todas las existencias son iguales? Algo de toda esta monotonía es la que percibimos en novelas como las de Heinrich Böll: una franja gris, sin sobresaltos; un electrocardiograma, que ya no registra variación alguna. Una novela como Asedio preventivo tiene que ver más con el rostro impersonal de los detectives y policías que con el drama de esa familia.

En contra de este parroquialismo, la novela latinoamericana podría aportar las virtudes de sus excesos; el desafuero de una imaginación carente de límites, en la cual la cultura popular, vigorosa en sus respuestas, tiñe lo incoloro de esta época; y lo vertiginoso de los diversos tiempos en que vivimos resulta atrapado por estructuras verbales, mucho más porosas y abiertas, tan flexibles que en ocasiones se desquician. Aquí residen los riesgos de una desmesura como Terra nostra. ¿Pero cómo no caer en ella si parte del descubrimiento de América y llega casi hasta el próximo siglo?

Los alemanes, tan bien educados (en apariencia) temen, como una peste, los riesgos de la intromisión. Es cierto que gracias a dicha asepsia pueden vivir (y morir) en paz, 
evitándose molestias y manteniendo una formativa autosuficiencia: cada cual debe valerse por sí mismo. Pero debido a ello, recortan de sus vidas el encantador tejido, a la vez superficial y complejo, de las relaciones a flor de piel.

Amistades, para siempre, a partir de una copa de más. Amores, eternos, edificados con base en un encuentro fugaz: tales eran los méritos latinoamericanos, tan afines a la volubilidad esencial de la especie humana. Los alemanes, en cambio, son serios. Buscan algo más firme y trascendente. Quieren durar. Y la culpable frivolidad latinoamericana siempre ha querido encontrar en ellos el contrapeso que le hace falta: de Thomas Mann a Heidegger, de Brecht a Keyserling, el influjo alemán en América Latina ha sido arrasador: no ha dejado nada. Apenas una pedantería que oculta la vacuidad. La pedantería del que quiere seguir siendo colonizado.

La verdadera tensión de la cultura alemana, de los románticos a Nietzsche, de Benn y Paul Celan al nuevo cine alemán, está todavía por elaborar. Sólo que Fitzcarraldo, como las novelas de Conrad, transcurre en los trópicos, en el verdadero corazón de las tinieblas, en el centro mismo del Amazonas. En los orígenes.

No dominar algo: dejarlo que suceda. Llegue, y haga. Nos destroce, inermes; o pase de largo, olvidadizos y negligentes. En los latinoamericanos hay al mismo tiempo un elemento de caos y otro de indolencia. Seres que actúan ante un influjo externo, prontos y arrebatados, y luego se sumergen en una plácida somnolencia. Nunca la continuidad. Nadie puede sacarlos de allí. No hay ningún imperativo moral que conminándolos los obligue a actuar. Se trata de una instintiva confianza en los destinos de la propia vida como una fuerza, más lúcida y avasallante, que sabe lo que hace. Como no hay término medio entre la realización o la catástrofe, todo es un don, y ella nos lo otorga. ¿Para qué entonces el esfuerzo sobrehumano de intentar orientarla si, en definitiva, estamos hechos con su propia materia, y ella la amolda a su antojo? Prodigalidad que no cesa y que vuelve fácil el duro oficio de vivir despojándolo, por cierto, de ese carácter de hazaña y sacrificio que el europeo, en tantas ocasiones, pretende atribuirle. Las jóvenes promesas latinoamericanas fracasan muy pronto y se tornan irónicas y desencantadas. Aprenden a vivir, siendo a la vez indulgentes y rapaces. Son cínicos. Los jóvenes ambiciosos europeos, por tener tres empleos y cumplir los horarios a tiempo, mueren de infarto a los 33 años. La vida, para ellos, como algo hecho por el hombre y que a veces engaña al hombre: tragedia. La vida, entre nosotros, como un pacto sucio, hecho con la vida misma, y que no parece lícito tomar demasiado en serio, pues a la vida, es bien sabido, le encanta hacer bromas: melodrama.

Borges, viejo de siglos y a la vez todavía tan sorprendente-mente joven como para continuar escribiendo poesía, dice en uno de sus últimos poemas:

Sé que he perdido tantas cosas que no podría contarlas y que esas perdiciones, ahora, son lo que es mío.

Sólo el que ha muerto es nuestro, sólo es nuestro lo que perdimos.

Todo poema, con el tiempo es una alegría.

Nuestras son las mujeres que nos dejaron, ya no sujetas a la víspera, que es zozobra, y a las alarmas y terrores de la esperanza.

No hay otros paraísos que los paraísos perdidos.

("Posesión de ayer", 1983).

En Europa es necesario hacer la cola. En Latinoamérica uno siempre está buscando los mecanismos picarescos para saltarse al que está delante de uno. Ardides y astucias no lícitas, es obvio, desde el punto de vista de una moral, pero al parecer válidas si se toma en cuenta la sola supervivencia física. En Europa la cola, de algún modo, te está señalando el camino, del vientre a la tumba, que debes seguir. El estudiante, en la universidad, si aspira a ser catedrático debe 
esperar a que el profesor muera; o contribuir, de algún modo, a acelerar su deceso; mientras tanto no tendrá más remedio que seguir allí, en la cola. La cola donde aguardará, impaciente, su turno para hacer lo que ya sabe que no le queda más remedio que hacer. Nada, pues ya todo está hecho.

Quizás por ello me conmovió, en Alemania, hallar dos instituciones donde en mitad del tiempo productivo se halla tiempo para otro tiempo más fecundo: el tiempo de perder el tiempo. Allí donde la compulsión de hacer cosas se atenúa; y el complejo de culpa ante el hecho irrefutable de producir algo no productivo desaparece. Me refiero a la "Konditorei", o pastelería para las señoras; y a la taberna, sobre todo en Múnich y la región bávara, para los hombres. En la "Konditorei" he visto a las viejas damas con su perro, su abrigo, su maquillaje y sus perfumes, eligiendo pasteles y conversando con las amigas, sin despojarse en ningún momento de sus sombreros, para todos los gustos. La verdadera civilización, en Europa como en América, en el café como en la "Konditorei", son esos rituales ya inconscientes, esas costumbres que se siguen sin saber por qué. Tres mujeres alemanas se reúnen y piden una botella de champaña. Parecen felices en su parloteo infatigable, y de seguro lo son. Están alegres.

Una vez terminada la botella miran los relojes, se despiden y se van. En ese momento quedé estupefacto: eran demasiado tacañas con su tiempo. Conscientes de haberlo invertido bien, no podían dilapidarlo. Se corría el riesgo de ser mucho más felices, de encontrar, gracias al estímulo combinado de la atmósfera y el alcohol, una verdad, aún no conocida, o una nueva desilusión. En Colombia, en cambio, me dije, todo hubiera sido distinto. Éramos un país tan pobre que lo único que teníamos en exceso era el tiempo, tiempo para botarlo y regarlo y malemplearlo. Tiempo que debía ser entregado a manos llenas, ocultando con ese derroche el remordimiento inevitable pero en el fondo dichoso por el margen de arbitrariedad que nos habíamos concedido.
No cumplimos con nosotros mismos, con lo que nuestra conciencia nos dicta, sino con esa ley mayor que nos rige, y que es indescifrable en sus últimos designios: las cosas había que llevarlas hasta su límite aun sabiendo que, quizás, en ese arrebato extremo sólo hallaremos, de nuevo, la frustración de la cual pretendíamos alejarnos. El deber inexorable que intentábamos, tahúres candorosos, engañar con tal estrépito. Habíamos perdido, de nuevo, un día; se nos había ido la vida, pero también, quién lo duda, habíamos sido felices. La frustración que es la otra cara de la dicha.

En América Latina no parecía necesario hacer un esfuerzo demasiado grande para ser feliz. Bastaba con estar allí, en el café, desocupados e indolentes, fabulando planes infalibles para ser ricos, seguros, de algún modo, de que la felicidad vendría y se sentaría a la mesa. En Europa la felicidad resultaba más prolija y elaborada. Aunque la relación se establece sin demasiados trámites previos, los sentidos se demoraban en responder a su presencia, como si una larga cautela hubiese amortiguado sus reacciones. El cuerpo, de algún modo, se había hecho rígido: se había educado, no para lo mejor, sino para controlar sus reacciones. Para mirarse a sí mismo, prisionero de una armazón que conviene aceitar con trotes, dietas y vitaminas.

Los hombres que beben en las cervecerías de Múnich - las mismas donde Hitler pronunció sus primeros discursos - y que conservan, en aparadores de metal, el jarro con su nombre y el pequeño barril con su cerveza preferida, se hallan, por su parte, cumpliendo también una rigurosa misa laica: están perdiendo el tiempo. Gritos exuberantes y el sentimentalismo fácil de la orquestica, la cual con sus melodías monótonas y sus sincopadas marchas militares, llena todo el ámbito. Así, todos ellos, se hallan entregados al cumplimiento de un ceremonial milenario. Ceremonia que sobrevive incluso a las infamias del turismo pero que debido precisamente a su vetustez, ya se ha hecho rígida. Es una defensa, no una apertura. Un último refugio.

Cuando el nacionalismo se exacerba, de nuevo, y el interés por la astrología, la cábala 
y el Oriente, crecen, de modo inexorable, estos hombres insisten en mantener vigente una actitud compartible: la de perder el tiempo. La de encontrar, entre la impersonalidad de las oficinas y el tedio de los impuestos y el hogar, un momento de humanidad, de escapatoria libremente elegida. Estos hombres, panzones y rubicundos, parecían dejar atrás el anuncio de una nueva catástrofe, y la estupidez cretinizante de la propaganda comercial por televisión, en el propósito, nunca soslayado, de encontrar calor y camaradería. De celebrar, juntos, un mismo alboroto compartido.

En ambos casos, en el café bogotano como en la taberna bávara, era visible el mismo mecanismo. Aquél que nos lleva a escribir novelas o a fabular poemas. A perder el tiempo, cultivando los sentidos, e indagando, en ese no hacer nada, por verdades básicas. Las que atañen a nuestro propio carácter, y a la convivencia con los otros; las que se refieren a nuestro tránsito sobre la tierra, que es siempre una relación entre personas: yo y el otro, los otros y yo. De allí arranca la novela: de un café, de una pastelería, de una jarra de cerveza, porque precisamente gracias a ellos, el alma se despliega. Molicie, pérdida del tiempo, entrega, no al fluir místico sino a lo más cotidiano, en esas pausas en las cuales recobramos la energía, las gentes piensan cosas quizás insustanciales pero necesarias: piensan en sí mismos, dialogan con los otros. Los negocios se suspenden y se oye, con una nitidez perturbadora, el transcurrir del tiempo. Ese mismo tiempo que toda escritura registra. Ahora, cuando las primeras máquinas de la inteligencia electrónica, con sus luces estrábicas y sus batallas galácticas, están a disposición de todos los niños, es obvio que ellas desplazarán a los últimos ingenios, arrinconados en los cafés y dedicados a resolver crucigramas, a descifrar el lenguaje. Una época se acaba. La misma, por ejemplo, que novelistas como Salvador Garmendia, en Venezuela, o Luis Fayad, en Colombia, vuelven, finalmente comprensibles, gracias a sus novelas. Pero sus novelas, al contrario de las novelasdiarios de Peter Handke, que siempre nos ofrecen la tautológica claustrofobia de alguien que se descompone, en infinitas sensaciones, bajo una lámpara de neón, tratan, por el contrario, de la peripecia de esos pequeños seres que aun a pesar de su reducción al punto límite, a la nada gozosamente conquistada, todavía son capaces de arrojar una titilante luz sobre el ámbito por donde se desplazan. Son como sombras iluminando oscuridades.

Se ha acostumbrado, de modo nocivo, a considerar la novela latinoamericana como próxima al mito, un tanto surrealizante, en el mal sentido de la palabra, dependiente del realismo mágico, etcétera, etcétera. Pero lo único cierto es que si los latinoamericanos escribimos novelas es porque aprendimos a hacerlo saqueando modelos europeos. Ahora, quizás, los europeos recobren algo de su menguada potencialidad narrativa, expoliando, una vez más, las riquezas de estas tierras, precozmente desérticas pero capaces aún de hacer con su tiempo perdido, con el pretendido desfase impuesto por la historia europea, algo propio y único. La Residencia en la tierra, de que hablaba Pablo Neruda. La Piedra de sol, que mencionaba Octavio Paz.

En algo que parece una novela, pero que es en realidad un ensayo - Respiración artificial, de Ricardo Piglia, 1980 - este autor argentino demuestra cómo Kafka y Hitler, en febrero de 1910, se encontraron en el café Arcos, de Praga, y conversaron largamente. Pero esta verdad poética es apenas metáfora de otra realidad más concreta: ¿por qué todo lo europeo, al llegar al trópico, se disuelve y se degrada, convirtiéndose en su más acerada parodia?

Parecería que el destino del Nuevo Mundo es reflejar, distorsionados y esperpénticos, los caracteres del Viejo, del mismo modo que el hijo satiriza al padre revelándole, como una afrenta, todo cuanto hay de incumplido en su vida. Todo el tiempo que perdió y que ahora, también, el hijo comienza a gastar, como si la herencia fuese eterna. Pero sabemos que las fuentes de los ríos también se secan y es necesario empezar a descubrir, por nuestra cuenta y riesgo, los métodos para sobrevivir, en medio del desierto. 